\title{
ISOTOPICALLY EXCHANGEABLE PHOSPHATE IN FRESHWATER SEDIMENTS: EFFECTS OF U.V.-IRRADIATION, FORMALDEHYDE, SOLID/SOLUTION RATIO, AND pH ON ITS EXPERIMENTAL DETERMINATION
}

\author{
L. H. VaAs ${ }^{1}$, R. N. J. Comans ${ }^{1}$, H. A. Das ${ }^{2}$, J. M. M. Reith ${ }^{1}$ and C. H. Van der Weideen ${ }^{1 *}$ \\ 'Department of Geochemistry, Institute of Earth Sciences, University of Utrecht, Budapestlaan 4, \\ 3584 CD Utrecht and ${ }^{2}$ Netheriands Energy Research Foundation (ECN), P.O. Box 1, 1755 ZG Petten, \\ The Netherlands
}

(Received December 1986)

\begin{abstract}
The influence of bioactivities, solid/solution ratio and the $\mathrm{pH}$ on the isotopic exchangeability of phosphate in a freshwater sediment was investigated. From the comparison of the results obtained for the same sample in the presence or absence of formaldehyde, it is concluded that microorganisms can effect the analysis for isotopically exchangeable phosphate. Irradiation with u.v.-light caused a sharp rise in isotopic exchangeability. In the $\mathrm{pH}$-range 6.6-8.4 isotopic exchangeability of phosphate increases with decreasing $\mathrm{pH}$-value which is attributed to an easier exchange of $\mathrm{H}_{2} \mathrm{PO}_{4}^{-}$than of $\mathrm{HPO}_{4}^{2-}$. The influence of the solid/solution ratio on the isotopic exchangeability of phosphate in the solid phase is small or nil. However, because of the relatively large amount of phosphate that goes into solution, the total isotopic exchangeability $E_{t}$ of phosphate in the solid and liquid phase together is strongly increased at a low solid/solution ratio. From these results it is concluded that in order to make a meaningful comparison of isotopically exchangeable phosphate in different soils or sediments it is essential to work at a nearly constant $\mathrm{pH}$ and solid/solution ratio. Such a comparison was made for 26 freshwater sediments from the Rhine/Meuse delta, in the presence and absence of $0.17 \mathrm{~mol}^{-1}$ formaldehyde as a biological inhibitor and it is concluded that addition of the latter is essential. The lowest total isotopic exchangeabilities of phosphate, (15-25) were measured in the sediments collected from the Haringvliet, whereas higher values (40-80) were found in the sediments from the Brielse Meer and the Grote Rug. This could well be indicative of a similar variance in the biological availability of the phosphate in the investigated sediments.
\end{abstract}

Key words-freshwater sediment, isotopically exchangeable phosphate, pH, phosphorus, radiophosphorus, sediment-water exchange, formaldehyde, u.v.-destruction, eutrophication

\section{INTRODUCTION}

The amount of biologically available phosphate in sediments or suspended matter is an important parameter for the quality of fresh water (Syers et al., 1973). Similarly, in soils the amount of biologically available phosphate determines whether or not phosphate is a limiting factor for growth. The best way to determine the availability of phosphate to biota is to use bioassays or pot experiments. However, these tests are often time-consuming and labour-intensive. Consequently much effort has been put into finding reliable alternative methods.

In the agricultural sciences isotopic dilution analysis is frequently used to determine the isotopic exchangeability ( $E$-value) of phosphate in soils (Amer, 1962; Becket and White, 1964; Mekhael et al., 1965; Amer et al., 1969; Ryden and Syers, 1977).

Li et al. $(1972,1973)$ used this method for freshwater sediments. Although there is no consensus

*To whom correspondence should be sent. about the precise meaning of isotopically exchangeable phosphate in soils or sediments it is generally agreed upon that such phosphate has a strong positive correlation with biologically available phosphate (Dalal and Hallsworth, 1977; Bowman et al., 1978; Bowman and Olsen, 1979; Le Mare, 1981; Venkat Reddy et al., 1982; Kucey and Bole, 1984). The main advantage of the isotopic dilution method is that the analysis can be done under natural conditions.

Three techniques of isotopic dilution analysis are used: carrier-free, with carrier, and inverse dilution. For most soils the choice of the method seems to be free. Only in the case of a high phosphate fixing capacity of the soil does the inverse dilution technique give better correlations with the results of greenhouse experiments (Dalal and Hallsworth, 1977).

When we compare the various experimental methods used to measure the $E$-value, striking differences are found in the $\mathrm{pH}$-control, solid/solution ratio and 
equilibration time. Evidently there is a lack of standardization. Therefore is it almost impossible to make a direct comparison between exchangeabilities found by different investigators. The purpose of this investigation was to determine the influence of biological processes, the solid/solution ratio and the $\mathrm{pH}$ on the isotopic exchangeability of phosphate in Dutch freshwater sediments. We studied the effect of bioactivities by determining the $E$-value of a sample in an untreated state, of the same sample irradiated with u.v.-light, and again of the same sample after addition of formaldehyde as a general biological inhibitor. Based upon the findings in these experiments a comparison was made of exchangeable phosphate in a number of sediments from the Rhine and the Meuse delta.

\section{THEORY}

The experimental procedure for determining the isotopically exchangeable phosphate can be expressed in the following manner. In the experiments $G$ (kg) sediment loaded with $c_{s o}\left(\mathrm{mg} \mathrm{P} \mathrm{kg}^{-1}\right)$ orthophosphate is suspended in $V$ litres of ionic medium yielding at equilibrium a phosphate concentration $c_{L}$ (mg P $\mathrm{l}^{-1}$ ) in the liquid phase and $c_{S}\left(\mathrm{mg} \mathrm{P} \mathrm{kg}^{-1}\right)$ in the solid phase.

The mass balance for the phosphate in this model is:

$$
c_{S o} G=c_{L} V+c_{S} G
$$

Then ${ }^{32} \mathrm{PO}_{4}$ is added, giving an initial ${ }^{32} \mathrm{PO}_{4}$-concentration $c_{L o}^{*}\left(\mathrm{~Bq}^{-1}\right)$ and, at equilibrium, a final concentration $c_{L}^{*}\left(\mathrm{~Bq}^{-1}\right)$ whereby a fraction $f=c_{L}^{*} / c_{L O}^{*}$ of the total quantity of ${ }^{32} \mathrm{PO}_{4}$ remains in solution.

This fraction $f$ is easily determined, because it is equal to the counting rate of an aliquot of the liquid phase divided by that of an aliquot of a blank solution to which an equal quantity of radioactivity had been added.

Defining $E$ as the fraction of the phosphate mass in the sediment which actually participates in the isotopic exchange, then according to the principles of isotopic dilution $f$ is also equal to the quotient of the mass of isotopically exchangeable phosphate in the solution $\left(=c_{L} V\right)$ and in the total system $\left(=c_{L} V+E c_{S} G\right)$.

After rearrangement and substitution of (1) for $E$ we find:

$$
E=\frac{(1-f) c_{L} V}{f\left(c_{S O} G-c_{L} V\right)}
$$

The total exchangeability $E_{t}$ in the system can be defined as the quotient of the mass of isotopically exchangeable phosphate and the total mass of phosphate:

$$
E_{t}=\frac{c_{L} V+E c_{S} G}{c_{S O} G}=\frac{c_{L}}{f c_{S O} G / V} .
$$

The values of $E$ and $E_{t}$ give directly the amount of isotopically exchangeable phosphate on the sediment $\left(E c_{S} \mathrm{mg} \mathrm{P} \mathrm{kg}^{-1}\right)$ and in the total system $\left(E_{t} c_{s o} \mathrm{mg} \mathrm{P} \mathrm{kg}^{-1}\right)$. It is obvious that these two quantities have the following relationship:

$$
E_{t} c_{S O}=\left(c_{S O}-c_{S}\right)+E c_{S} .
$$

Here $\left(c_{S O}-c_{S}\right)$ represents the orthophosphate which has gone into solution. $E_{t}$ is the best measure for the isotopic exchangeability of phosphate in a given sediment, because it includes both the contribution of the phosphate that has remained on the sediment and the contribution of the dissolved phosphate which, by definition, is $100 \%$ isotopically exchangeable.

\section{MATERIALS AND METHODS}

\section{Samples}

Two samples were used to investigate the influence of biological processes, the solid/solution ratio, and the $\mathrm{pH}$ on the exchangeability of phosphate. The first (M1) was a mixture of suspended particulate matter from freshwater in the Rhine/Meuse delta.

This particulate matter was collected at various locations (Nieuwe Merwede, Hollands Diep, Haringuliet) with a continuous-flow centrifuge. The second sample (L2) was a sediment collected at one site in the Brielse Meer. Three extraction techniques were used to characterize these samples (Hieltjes and Lijklema, 1980):

(1) $1.0 \mathrm{M}\left(\mathrm{mol} \mathrm{l}^{-1}\right) \quad \mathrm{NH}_{4} \mathrm{Cl}$-extractable $\mathrm{PO}_{4}$ (loosely bound)

(2) $0.1 \mathrm{M} \mathrm{NaOH}$-extractable $\mathrm{PO}_{4}$ (Al- and Fe-bound)

(3) $0.5 \mathrm{M} \mathrm{HCl}$-extractable $\mathrm{PO}_{4}$ (Ca-bound).

The total phosphorus content $c_{s o}$ was determined after destruction of the samples with $\mathrm{H}_{2} \mathrm{SO}_{4} / \mathrm{K}_{2} \mathrm{~S}_{2} \mathrm{O}_{8}$ in an autoclave at 2 bar (Eisenreich et al., 1975). Table 1 shows the results of these chemical analyses.

Stock suspensions of samples $M 1$ and L2, each with a particle size $<2 \mu \mathrm{m}$ were prepared by suspending the samples in $10^{-2} \mathrm{M} \mathrm{NaCl}$. The solid/solution-ratio was then determined by evaporating a known volume to dryness followed by a drying period of $12 \mathrm{~h}$ at $383 \mathrm{~K}$. The solid/solution ratio was found by weighing and correcting for the weight of the dissolved $\mathrm{NaCl}$. All sampling from the stock suspensions and from the suspensions in the experiments was done with a pipette while the suspensions were being stirred thoroughly in order to maintain a constant solid/solution-ratio. This technique was checked by weighing and proved to be reliable.

\begin{tabular}{|c|c|c|c|c|}
\hline Sample & $\left.\left(\mathrm{mg} \mathrm{P}_{\mathrm{sg}}^{c_{\mathrm{kg}}}\right)^{-1}\right)$ & $\begin{array}{c}\mathrm{NH}_{4} \mathrm{Cl}-\mathrm{P} \\
\left(\mathrm{mg} \mathrm{P}_{\mathrm{Pg}} \mathrm{kg}^{-1}\right)\end{array}$ & $\begin{array}{c}\mathrm{NaOH}-\mathrm{P} \\
\left(\mathrm{mg} \mathrm{P} \mathrm{kg}^{-1}\right)\end{array}$ & $\begin{array}{c}\mathrm{HCl}-\mathrm{P} \\
\left(\mathrm{mg} \mathrm{P} \mathrm{kg}{ }^{-1}\right)\end{array}$ \\
\hline M1 & 5400 & 90 & 4100 & 30 \\
\hline L2 & 3300 & 50 & 2300 & 50 \\
\hline
\end{tabular}

In some cases part of the stock suspension of sample M1 was irradiated for $24 \mathrm{~h}$ with u.v.-light. The irradiation took

Table 1. Discrete inorganic $P$ fractions in samples $M 1$ and L2 
place in a photochemical reactor with quartz immersion well (Ace Glass Inc.) equipped with a $450 \mathrm{~W}$ medium pressure Hg-lamp (Hanovia); during the irradiation the temperature of the suspension stayed below $308 \mathrm{~K}$. At the start of the irradiation $0.02 \mathrm{M} \mathrm{H}_{2} \mathrm{O}_{2}$ was added (Armstrong et al., 1966, 1968).

Twenty-six sediment samples from the Rhine/Meuse delta were used for the comparison of phosphate exchangeability and were taken from undisturbed cores collected at locations in the Brielse Meer, Haringvliet, and Grote Rug. These samples were taken from the oxidized and/or reduced zones in the sediment cores. These zones were distinguished either visually on the basis of colour difference or electrochemically by measurement of the redox potential. Most of the water in the pores of the sediments was removed using a filter-press at 6 bar nitrogen pressure. Then the samples were freeze-dried and homogenized. Preparation, sampling and determination of the solid/solution-ratio of the stock suspensions in $10^{-2} \mathrm{M} \mathrm{NaCl}$ were the same as for the two test samples (M1 and L2).

The first four columns of Table 6 give the code of the sediment core, the origin of the core, the state of oxidation of the sub-sample and the total phosphate content $c_{S O}$ respectively. When the codes in the table are identical this means that sub-samples were taken from both the oxidized and the reduced zone of the same sediment core. Only in the case of cores A9 and A10 were two samples taken from the reduced zone, the second being taken at a greater depth in the core.

\section{Experimental procedures}

The sample containers used were of polyethylene and were cleaned with $6 \mathrm{M} \mathrm{HCl}$. The possible interference by adsorption of phosphate on the container wall was investigated over a period of 24 days. Adsorption at $\mathrm{pH} 7$ and 8 (ionic medium $2 \times 10^{-3} \mathrm{M} \mathrm{KCl}$ ) proved to be $<4 \%$ for aqueous concentrations exceeding $0.1 \mathrm{mg} \mathrm{Pl}^{-1}$.

Preliminary experiments with sediments from the Rhine/Meuse delta frequently yielded irrational and irreproducible exchangeabilities. This was presumed to be the result of biological activities. Samples from a sediment core were used to investigate the influence of formaldehyde $\left(\mathrm{CH}_{2} \mathrm{O}\right)$ concentration between 0.003 and $0.17 \mathrm{M}$. Based on these results (cf. Table 5) all experiments were repeated in the presence of $0.17 \mathrm{M} \mathrm{CH} \mathrm{CH}_{2} \mathrm{O}$ as a general biological inhibitor, as was earlier used by Pomeroy et al. (1965).

Consequently the following experimental procedure was chosen. Aliquots of $75 \mathrm{ml}$ suspension of the samples with known solid/solution-ratio in $10^{-2} \mathrm{M} \mathrm{NaCl}$ were prepared. Optionally $1 \mathrm{ml} 35 \% \mathrm{CH}_{2} \mathrm{O}$ was added to give a concentration of $0.17 \mathrm{M}$ (Pomeroy et al., 1965).

In all experiments samples were continuously agitated by placing the containers with sample suspensions on a reciprocating shaker mounted in a waterbath kept at $298 \pm 1 \mathrm{~K}$.

After 20 days of contact time $20 \mathrm{ml}$ of suspension was centrifuged $\left(20 \mathrm{~min}\right.$ at $\left.2 \times 10^{4} \mathrm{~m} \mathrm{~s}^{-2}\right)$ and used to determine $c_{L}$ (Murphy and Riley, 1962). Then $1 \mathrm{ml}(75 \mathrm{kBq})$ ${ }^{32} \mathrm{PO}_{4}$-solution, with a negligible amount of ${ }^{31} \mathrm{PO}_{4}$-carrier, was added. After 27, 29 and 31 days the $\mathrm{pH}$ of the suspension was measured and $2 \mathrm{ml}$ of suspension was centrifuged and used to determine $c_{L}^{*}$ by means of Cerenkov-counting (Packard 2425 liquid scintillation counter). Some samples were slightly coloured; colour-quenching was corrected for by the channels-ratio method. After 34 days the $\mathrm{pH}$ of the suspensions was measured again and $c_{L}$ and $c_{L}^{*}$ were determined. In the experiments on the $\mathrm{pH}^{-}$ influence the $\mathrm{pH}$ was adjusted three times a week by the addition of dilute solutions of $\mathrm{NaOH}$ or $\mathrm{HCl}$.

\section{RESULTS AND DISCUSSION}

Preliminary experiments showed that phosphate was released slowly into the liquid phase of the

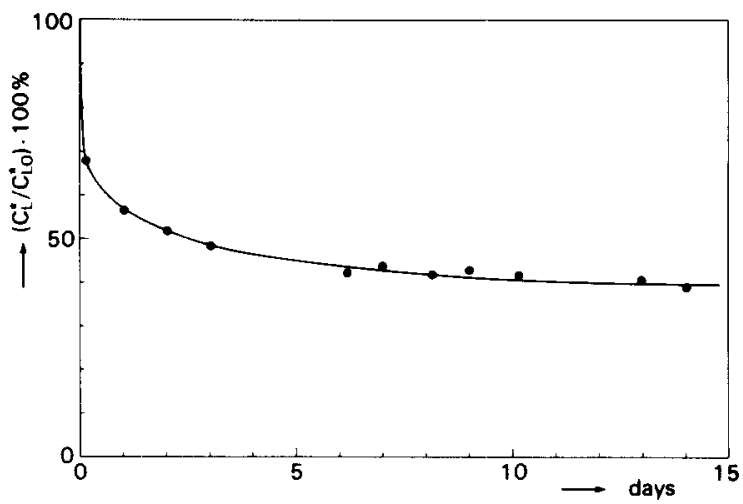

Fig. 1. Typical example of the kinetics of the isotopic exchange of ${ }^{32} \mathrm{PO}_{4}$ with stable phosphate in sediment samples (sample L2, Table 2 column 4). The ordinate represents the activity of ${ }^{32} \mathrm{P}$ in solution, expressed as a percentage of the amount of radiotracer originally added to the solution.

sample suspensions. Only after 2-3 weeks of continuous agitation did the suspensions reach a state of constant phosphate concentration in the solution $\left(c_{L}\right)$.

As illustrated in Fig. 1, the subsequent addition of ${ }^{32} \mathrm{PO}_{4}$ (without disturbing the volume of the system or the mass of ${ }^{31} \mathrm{PO}_{4}$ ) resulted in an initially rapid uptake of the radiotracer after about 7 days, followed by a slow decrease in the tracer concentration in the solution $\left(c_{L}^{*}\right)$. In all experiments isotopic equilibrium had not been reached within 14 days.

In order to estimate the final $c_{L}^{*}$ we used the approach of Ryden et al. (1977) by plotting $c_{L}^{*}$ vs the reciprocal value of the exchange-time and extrapolated to $t^{-1}=0$. This was done by means of linear regression using values obtained after $7,9,10$ and 14 days (Fig. 2). These $t^{-1}$ plots do not imply more than being a method to obtain extrapolated values that can be compared. The time scale is still one in weeks, which is appropriate for the rate of isotopic exchange that is of interest for the purpose of this study. The extrapolated values never deviated by more than $15 \%$ from the last measured values of $c_{L}^{*}$. It was further observed that the $\mathrm{pH}$ variations were small

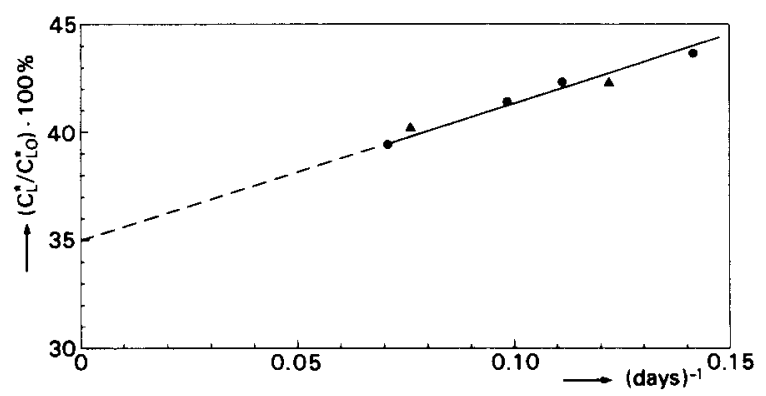

Fig. 2. Example of the extrapolation method proposed by Ryden et al. (1977) applied on data points shown in Fig. 1. The dots indicate the data for the time intervals used in the standard procedure as described in the text $(7,9,10$ and 14 days), the triangles indicate data obtained for two intermediate measurements ( 8 and 13 days). 
Table 2. Isotopically exchangeable phosphate in sample $\mathrm{M} 1$

\begin{tabular}{lccc}
\hline & $\begin{array}{c}\text { No treatment } \\
(n=5)\end{array}$ & $\begin{array}{c}\text { Addition of } \mathrm{CH}_{2} \mathrm{O} \\
(n=5)\end{array}$ & $\begin{array}{c}\text { u.v.-irradiated } \\
(n=8)\end{array}$ \\
\hline $\mathrm{pH}$ & $7.51 \pm 0.06$ & $7.66 \pm 0.03$ & $7.33 \pm 0.05$ \\
$G / V\left(\mathrm{~g} \mathrm{I}^{-1}\right)$ & 0.899 & 0.887 & 0.418 \\
$c_{L}\left(\mathrm{mg} \mathrm{P} \mathrm{I}^{-1}\right)$ & $0.80 \pm 0.01$ & $0.82 \pm 0.01$ & $0.60 \pm 0.01$ \\
$c_{S}\left(\mathrm{mg} \mathrm{Pg}^{-1}\right)$ & $4510 \pm 10$ & $4470 \pm 10$ & $3960 \pm 30$ \\
$\left(c_{S O}-c_{S}\right)\left(\mathrm{mg} \mathrm{Pg}^{-1}\right)$ & $890 \pm 10$ & $930 \pm 10$ & $1440 \pm 30$ \\
$f$ & $0.41 \pm 0.02$ & $0.54 \pm 0.01$ & $0.36 \pm 0.01$ \\
$E$ & $0.28 \pm 0.02$ & $0.18 \pm 0.01$ & $0.66 \pm 0.03$ \\
$E c_{S}\left(\mathrm{mg} \mathrm{P} \mathrm{kg}^{-1}\right)$ & $1300 \pm 100$ & $790 \pm 40$ & $2600 \pm 100$ \\
$E_{t}$ & $0.40 \pm 0.02$ & $0.32 \pm 0.01$ & $0.75 \pm 0.02$ \\
$E_{t} c_{S O}\left(\mathrm{mg} \mathrm{P} \mathrm{kg}^{-1}\right)$ & $2200 \pm 100$ & $1720 \pm 40$ & $4100 \pm 100$ \\
\hline
\end{tabular}

(SD<0.25). Therefore no attempt was made to control the $\mathrm{pH}$ of the sample suspensions.

Effect of irradiation with u.v.-light and of the addition of formaldehyde

Table 2 shows the isotopic exchangeability of phosphate in sample $\mathrm{M} 1$, in the same sample after irradiation with u.v.-light and in the presence $0.17 \mathrm{M}$ $\mathrm{CH}_{2} \mathrm{O}$.

In order to get an impression of the reproducibility, the experiments were repeated 5-8 times; the table gives the mean values and the standard deviations. Since the results of the analysis for isotopically exchangeable phosphate are reproducible, it is concluded that the method is satisfactory. It is reasonable to assume that in the experiments with $\mathrm{CH}_{2} \mathrm{O}$ or in the experiments using u.v.-irradiated material, no biological activities took place (Pomeroy et al., 1965; Jackson and Schindler, 1975). The effect of u.v.-irradiation is less general but most microorganisms are inactivated (Harm, 1980). Furthermore quite a number of organic phosphates are known to be mineralized to inorganic phosphate by irradiation with u.v.-light (Armstrong et al., 1966, 1968).

The differences between the results for sample $\mathrm{M} 1$ in the presence and absence of $\mathrm{CH}_{2} \mathrm{O}$ is at least partly due to bioactivities. The absence of $\mathrm{CH}_{2} \mathrm{O}$ leads to a slightly higher isotopic exchangeability. One can argue that coating of inorganic particles by $\mathrm{CH}_{2} \mathrm{O}$ might have a similar effect, but it will be shown for experiments with 26 sediment samples that this, if at all, is not the main reason for the observed differences. Because in both cases the values of $c_{S}$ are about equal, the increased total isotopic exchangeability $E_{t}$ in the absence of $\mathrm{CH}_{2} \mathrm{O}$ is, according to equation (4), merely the result of the increased $E$ value.

Comparison of the results obtained in the presence of $\mathrm{CH}_{2} \mathrm{O}$ with those for the u.v.-irradiated sample $\mathrm{M} 1$ shows a spectacular rise of $2400 \mathrm{mg} \mathrm{P} \mathrm{kg}^{-1}$ in $E_{t} c_{s o}$ [equation (4)] upon irradiation. About $500 \mathrm{mg} \mathrm{P} \mathrm{kg}^{-1}$ of this rise can be explained by the influence of the lower $G / V$-ratio in the u.v.-irradiated experiment (cf. pertinent paragraph), which results in an increased value for $\left(c_{S o}-c_{S}\right)$. After irradiation with u.v.-light a reduction of $42 \mathrm{~g} \mathrm{C} \mathrm{kg}^{-1}$ in the organic carbon content was found in sample $\mathbf{M} 1$, using the method of Sims and Haby (1971). On the basis of a $\mathrm{C} / \mathrm{P}$-weight ratio of $40: 1$ (using an overall formula of $\mathrm{C}_{106} \mathrm{H}_{263} \mathrm{O}_{110} \mathrm{~N}_{16} \mathrm{P}$ for algal protoplasm) the estimated u.v.-mineralization of biologically/ organically bound $\mathrm{PO}_{4}$ is then $1000 \mathrm{mg} \mathrm{P} \mathrm{kg}^{-1}$ at most. So the presence of biologically or organically bound phosphate can only explain part of the rise in $E_{t} c_{s o}$ [Equation (4)]. Possibly one of the extra effects of u.v.-irradiation is the activation of inorganic phosphates (sample M1: $900 \mathrm{mg} \mathrm{P} \mathrm{kg}^{-1}$ or more) that do not normally participate in isotopic exchange reactions.

Two explanations for this behaviour are proposed. Firstly: an attenuation of the bonds of (chemi)sorbed phosphate; secondly: removal of adsorbed organic compounds that form a protective coating on phosphate groups at the surface of solid phases.

When the results of Tables 1 and 2 are compared, it is clear that not all phosphate that is supposedly bound in or adsorbed on aluminium or iron oxides or

Table 3. Effect of the pH on the $E$ - or $E_{\mathrm{t}}$-value of phosphate in sediment L2

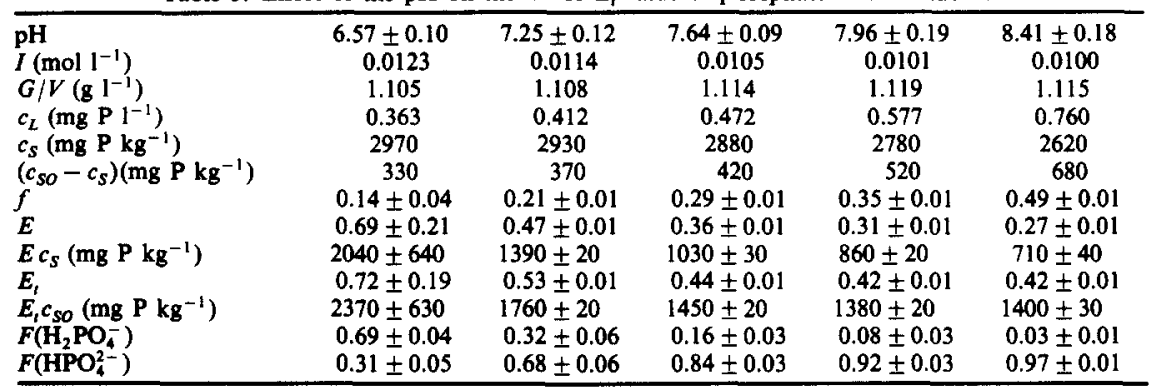


oxihydroxides present in sample $\mathrm{M1}$ is isotopically exchangeable $(\sim 40 \%)$.

Effect of the $\mathrm{pH}$ on isotopically exchangeable phosphate

Table 3 shows the effect of the $\mathrm{pH}$ on the isotopic exchangeability of phosphate in sediment $\mathrm{L} 2$ in the presence of $0.17 \mathrm{M} \mathrm{CH}_{2} \mathrm{O}$. These experiments were carried out in duplicate at $5 \mathrm{pH}$-values ranging from 6.6 to 8.4. The mean values and standard deviations are given in the table. The agreement between the duplicates was good except at $\mathrm{pH} 6.6$ where large differences were observed. An unavoidable result of the $\mathrm{pH}$-corrections, especially in the experiments at low $\mathrm{pH}$-value, was the rise in ionic strength. The change in ionic strength was calculated from the quantities of added $\mathrm{HCl}$ or $\mathrm{NaOH}$. It was assumed that only $\mathrm{Na}^{+}$and $\mathrm{Cl}^{-}$contributed to this increase. In interpreting the results we assumed that the influence of the rise in ionic strength on the isotopic exchangeability could be neglected.

The results show clearly a decrease of $E c_{s}$ (equation (4)] with increasing $\mathrm{pH}$-value. At higher $\mathrm{pH}$ values this $\mathrm{pH}$-effect is masked in the total exchangeability $E_{t}$ because the drop in $E c_{S}$ [equation (4)] is compensated for by the rise in $\left(c_{S o}-c_{S}\right)$, which is due to partial desorption/dissolution of phosphate at the higher $\mathrm{pH}$-values. The fact that, in the investigated $\mathrm{pH}$-range, $E$ and $t$ are high at low $\mathrm{pH}$ values suggests that $\mathrm{H}_{2} \mathrm{PO}_{4}^{-}$is more easily exchanged than $\mathrm{HPO}_{4}^{2-}$.

To investigate this suggestion we calculated the species distribution of $\mathrm{H}_{3} \mathrm{PO}_{4}$ at the $\mathrm{pH}$-values of Table 3. In this calculation we used $\mathrm{p} K_{1}=2.15$, $\mathrm{p} K_{2}=7.06$ and $\mathrm{p} K_{3}=12.07$ as equilibrium constants for the dissociation steps of $\mathrm{H}_{3} \mathrm{PO}_{4}$ at ionic strength $10^{-2} \mathrm{M}$ (Stumm and Morgan, 1981) and as activity constants we took values which had been estimated with the Davies equation (Stumm and Morgan, 1981). From the dissociation constants of $\mathrm{H}_{3} \mathrm{PO}_{4}$, given by Stumm and Morgan (1981) it turns out (cf. Table 3) that in the pH-range of the experiments only $\mathrm{H}_{2} \mathrm{PO}_{4}^{-}$and $\mathrm{HPO}_{4}^{2-}$ are important. Although not measured, the $\mathrm{Ca}$ and $\mathrm{Mg}$ concentration eventually generated by partial dissolution of the suspended solids, are assumed to be low enough to justify the neglect of complexing of the monohydrogen phosphate anion in $\mathrm{Ca}$ and $\mathrm{Mg}$ complexes (log $\bar{K}$ respectively 2.7 and 2.5; Stumm and Morgan, 1981).
Without the use of the less precise measurements at $\mathrm{pH} 6.6$ we found the following relationships between the exchangeabilities and the fraction of the dihydrogenphosphate ion

$$
\alpha_{\mathrm{H}_{2} \mathrm{PO}_{4}^{-}}=\left(\mathrm{H}_{2} \mathrm{PO}_{4}^{-}\right) /\left(\mathrm{PO}_{4}\right)_{\mathrm{T}}
$$

by means of linear regression:

$$
\begin{array}{ll}
E=0.25+0.68 \alpha_{\mathrm{H}_{2} \mathrm{PO}_{4}^{-}} & (r=1.00) \\
E=0.39+0.41 \alpha_{\mathrm{H}_{2} \mathrm{PO}_{4}^{-}} & (r=0.96) .
\end{array}
$$

The high, positive correlation coefficients sustain the suggestion that $\mathrm{H}_{2} \mathrm{PO}_{4}^{-}$is the species which is easily exchanged. Atkinson et al. (1972) discussed the influence of $\mathrm{pH}$ on the rate of isotopic exchange of phosphate at the goethite-aqueous solution interface. They explained the increase of this rate with decreasing $\mathrm{pH}(\mathrm{pH}<9)$ by catalysis involving protonation of one oxygen in the $\mathrm{Fe}_{\mathrm{s}}-\mathrm{O}-\mathrm{P}-\mathrm{O}-\mathrm{Fe}_{\mathrm{s}}$ bonds (s stands for surface sites) leading to a single bonded $\mathrm{Fe}_{\mathrm{s}}-\mathrm{OPO}(\mathrm{OH})_{2}$ surface complex. Mutatis mutandis this is essentially quite similar to the explanation as given by us.

In the pH-region 7.6-8.4 the influence of the $\mathrm{pH}$ on $E$ or $E_{t}$ is not large. Therefore, as long as one is dealing with small differences in this $\mathrm{pH}$-range, exchangeabilities of different sediments can be compared. Next to the results of Atkinson et al. (1972), little is known from literature about the pH-effect on isotopic exchangeability. Murmann and Peech (1969) reported the opposite effect for 53 different soils in $10^{-2} \mathrm{M} \mathrm{CaCl}_{2}$ as ionic medium. The precipitation of $\mathrm{Ca}-\mathrm{PO}_{4}$-compounds may have been responsible for this. White and Taylor (1977) found practically no $\mathrm{pH}$-effect between $\mathrm{pH} 5.2$ and 6.9 with a clay loam suspended in $2 \times 10^{-3} \mathrm{M} \mathrm{CaCl}_{2}$.

Comparison of Tables 1 and 3 shows that at the same $\mathrm{pH}$ as used for sample Ml (Table 2), the isotopic exchangeable phosphate is about $60 \%$ of the amount of phosphate, that is mainly present in/at aluminium or iron oxide phases.

\section{Effect of the solid/solution-ratio on isotopically exchangeable phosphate}

Table 4 shows the influence of the solid/solution ratio on the $E$ - and $E_{t}$-values of sediment $\mathrm{L} 2$ in the

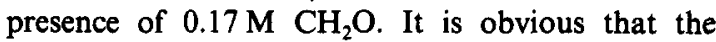
relative errors in $E$ and $E c_{S}$ must be large at low $G / V$-values due to the high $f$-values and the resulting

\begin{tabular}{|c|c|c|c|c|c|c|}
\hline 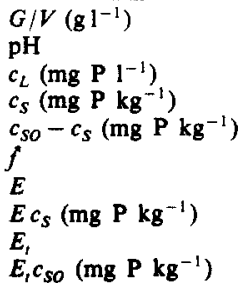 & $\begin{array}{c}0.0936 \\
7.66 \pm 0.05 \\
0.227 \\
880 \\
2420 \\
0.91 \\
0.27 \pm 0.09 \\
240 \pm 80 \\
0.81 \pm 0.04 \\
2670 \pm 130\end{array}$ & $\begin{array}{c}0.187 \\
8.01 \pm 0.18 \\
0.426 \\
1030 \\
2270 \\
0.86 \\
0.36 \pm 0.05 \\
370 \pm 80 \\
0.80 \pm 0.04 \\
2640 \pm 130\end{array}$ & $\begin{array}{c}0.375 \\
8.16 \pm 0.09 \\
0.642 \\
1590 \\
1710 \\
0.75 \\
0.36 \pm 0.05 \\
580 \pm 70 \\
0.70 \pm 0.05 \\
2290 \pm 120\end{array}$ & $\begin{array}{c}0.749 \\
8.03 \pm 0.05 \\
0.662 \\
2420 \\
880 \\
0.54 \\
0.31 \pm 0.02 \\
760 \pm 60 \\
0.50 \pm 0.02 \\
1640 \pm 80\end{array}$ & $\begin{array}{c}1.50 \\
7.93 \pm 0.02 \\
0.668 \\
2850 \\
450 \\
0.35 \\
0.29 \pm 0.02 \\
830 \pm 50 \\
0.39 \pm 0.02 \\
1270 \pm 60\end{array}$ & $\begin{array}{c}3.00 \\
7.86 \pm 0.06 \\
0.705 \\
3070 \\
230 \\
0.23 \\
0.26 \pm 0.01 \\
800 \pm 40 \\
0.31 \pm 0.02 \\
1030 \pm 50\end{array}$ \\
\hline
\end{tabular}
uncertainty in the $(1-f)$-term [see equation (2)]. The

Table 4. Effect of $G / V$ ratio on the $E$ - or $E_{t}$-value of phosphate in sediment $L 2$ 
Table 5. Influence of the concentration of formaldehyde on isotopically exchangeable phosphate in the oxidized zone of sediment core A4

\begin{tabular}{lllllllllll}
\hline $\mathrm{CH}_{2} \mathrm{O}\left(\mathrm{mol} \mathrm{1}^{-1}\right)$ & 0 & 0 & 0.003 & 0.005 & 0.011 & 0.021 & 0.043 & 0.085 & 0.170 & 0.170 \\
$\mathrm{pH}$ & 8.27 & 8.34 & 7.58 & 7.22 & 8.63 & 8.60 & 8.62 & 8.42 & 8.40 & 8.39 \\
$\mathrm{G} / \mathrm{V}\left(\mathrm{g} \mathrm{l}^{-1}\right)$ & 1.34 & 0.994 & 0.625 & 0.625 & 0.625 & 0.625 & 0.625 & 0.625 & 1.16 & 1.33 \\
$c_{L}\left(\mathrm{mg} \mathrm{k}^{-1}\right)$ & 0.206 & 0.225 & 0.158 & 0.143 & 0.251 & 0.245 & 0.238 & 0.216 & 0.239 & 0.214 \\
$f$ & 0.065 & 0.029 & 0.12 & 0.064 & 0.24 & 0.23 & 0.23 & 0.21 & 0.11 & 0.12 \\
$E_{1}$ & 1.12 & 3.68 & 1.00 & 1.71 & 0.79 & 0.82 & 0.78 & 0.77 & 0.88 & 0.66 \\
\hline
\end{tabular}

standard deviations in the calculated isotopic exchangeabilities were estimated from the relative errors of $3,2 \frac{1}{2}$ and $3 \%$ in the determination of $c_{L}, G / V$ and $f$ respectively. The influence of the $\mathrm{pH}$ on the results was neglected since the differences in the pH-value were small.

The $G / V$-ratio has practically no effect on the $E$-value. However, the total exchangeability $E_{t}$ is strongly increased at low $G / V$-ratio. This is caused by the influence of $G / V$ on $\left(c_{s o}-c_{S}\right)$. At the lowest value of $G / V$, about $70 \%$ of the total phosphate content, $c_{s o} G$ is dissolved/desorbed but this percentage continuously drops to about $7 \%$ at the highest value of $G / V$. Theoretically $E_{t}$ approaches unity as $G / V$ approaches zero because at extremely low $G / V$-values $c_{L} V=c_{S O} G$ and $f=1$, so $E_{t}=1$ [equation (3)]. The experiments of this investigation seem to agree with this boundary condition.

De Bussetti et al. (1977), using 0.1-1.4 $\mathrm{g}^{-1}$ aqueous suspensions of model compounds like hydroxyapatite and amorphous $\mathrm{AlPO}_{4}$, found the same reduction in $E_{t}$ with increasing solid/solution-ratio. These results deviate from the results of Bowman and Olsen (1979) obtained with a silty clay loam suspended in water at pH-values between 7.9 and 8.4. They found that the $G / V$-ratio had no effect on $E_{t}$ at high $G / V$-values $\left(50-400 \mathrm{~g}^{-1}\right)$ probably because the relative contribution of $\left(c_{s o}-c_{S}\right)$ in $E_{t} c_{s o}$ [equation (4)] is much smaller there. The isotopic exchangeability seems to be complete (cf. Tables 1 and 4) at the lowest values of the solid/solution-ratio but decreases to about $45 \%$ at the highest value.

It is concluded that it is important to work at nearly constant solid/solution-ratio if one's objective is to compare the isotopic exchangeabilities of different soils or sediments.

\section{Application to sediments from the Rhine/Meuse delta}

As was already mentioned under "experimental procedures", irreproducible and irrational results were sometimes obtained that allegedly were caused by biological activity. Therefore, one of the samples collected in the area was used to study the effect of the concentration of $\mathrm{CH}_{2} \mathrm{O}$ between 0.0 and $0.17 \mathrm{M}$. The results are shown in Table 5 . All but two $\mathrm{pH}$-values fall within a small range. The reason for these two lower pH-values is not understood. However, their influence and the effect of the differences in solid/solution-ratio cannot invalidate the conclusion that, with this particular sediment, at $\mathrm{CH}_{2} \mathrm{O}$ concentrations below $10^{-2} \mathrm{M}$ irrational and irre- producible results are obtained. Therefore, in accordance with the experimental conditions used by Pomeroy et al. (1965), a concentration 20 times as strong, namely $0.17 \mathrm{M} \mathrm{CH}_{2} \mathrm{O}$, was used in the routine experiments.

Table 6 shows the total isotopic exchangeability $E_{t}$ of phosphate in the 26 sediment samples ( 18 sediment cores) investigated. The table gives the results of the duplicate experiments in the presence and absence of $0.17 \mathrm{M} \mathrm{CH} \mathrm{CH}_{2} \mathrm{O}$. In no case was equilibrium in the isotopic exchange established within 14 days of tracer addition and therefore the value of $f$ was estimated using the extrapolation method (Fig. 2).

In order to indicate the differences in the solid/ solution-ratio and in the $\mathrm{pH}$, we give in Table 6 the mean values and standard deviations of these parameters. These values are based on the four experiments with each separate sediment. For all 104 experiments together the mean solid/solution-ratio is $1.09 \pm 0.09 \mathrm{~g} \mathrm{l}^{-1}$ and the mean $\mathrm{pH}$ is $8.10 \pm 0.25$. In a foregoing paragraph it was concluded that the influence of $G / V$ and of the $\mathrm{pH}$ on the $E_{t}$-value can be neglected if the differences in $G / V$ and $\mathrm{pH}$ are small. It appears that these conditions are fulfilled and therefore the $E_{t}$-values of the various sediments can be compared directly. In the group of sediment cores A1-A6 many irreproducible and irrational $\left(E_{t}<1\right)$ exchangeabilities were found in the absence of $\mathrm{CH}_{2} \mathrm{O}$. The corresponding experiments are characterized by a relatively strong reduction in the fraction of the radiotracer remaining in solution in the period 7-14 days after tracer addition. Apparently one is dealing with a situation that is well out of equilibrium. Only a small fraction of the total phosphate, $c_{S O}$, is yielded to the solution, giving rise to a phosphate concentration, $c_{L}$. To this solution radiotracer is added. When growth of the biological phase occurs at the expense of the dissolved and most labile phosphate, containing most of the labeled phosphate, it can be understood that this excess uptake of the radiotracer leads to an artificially high value of exchangeable phosphate. As a result the $f$-value found by extrapolation is unreliable. These problems are eliminated by the addition of $\mathrm{CH}_{2} \mathrm{O}$, which suggests that the deviations are caused by phosphate consumption by microorganisms attached to the sediment. The phosphate that is consumed must be supplied by the sediment, because the phosphate concentration in the solution remains constant. In this situation of phosphate transport the steady state condition is not fulfilled, which implies that 
Table 6. Total isotopic exchangeability of phosphate in 26 freshwater sediments from the Rhine/Meuse-estuary

\begin{tabular}{|c|c|c|c|c|c|c|c|c|c|}
\hline \multirow[b]{3}{*}{ Core } & \multirow[b]{3}{*}{ Origin* } & \multirow[b]{3}{*}{ Redox state } & \multirow{3}{*}{$\begin{array}{c}c_{s o} \\
\left(\mathrm{mg} \mathrm{Pg}^{-1}\right)\end{array}$} & \multirow[b]{3}{*}{$\mathrm{pH}$} & \multirow{3}{*}{$\begin{array}{c}G / V \\
\left(\left.\mathrm{~g}\right|^{-1}\right)\end{array}$} & \multicolumn{4}{|c|}{$E_{\text {f }}$} \\
\hline & & & & & & \multicolumn{2}{|c|}{ No $\mathrm{CH}_{2} \mathrm{O}$} & \multicolumn{2}{|c|}{$+\mathrm{CH}_{2} \mathrm{O}$} \\
\hline & & & & & & 1 & 2 & 3 & 4 \\
\hline Al & G.R. & Ox. & 2400 & $8.26 \pm 0.07$ & $1.08 \pm 0.26$ & 0.73 & 1.10 & 0.60 & 0.55 \\
\hline Al & G.R. & Red. & 1450 & $8.42 \pm 0.11$ & $1.13 \pm 0.15$ & 0.77 & 0.75 & 0.58 & 0.53 \\
\hline $\mathrm{A} 2$ & G.R. & Ox. & 2200 & $8.16 \pm 0.18$ & $1.14 \pm 0.14$ & 1.48 & 0.82 & 0.63 & 0.55 \\
\hline$A 2$ & G.R. & Red. & 1500 & $8.23 \pm 0.12$ & $1.16 \pm 0.15$ & 1.94 & 0.65 & 0.52 & 0.51 \\
\hline A3 & G.R. & Ox. & 2050 & $8.17 \pm 0.22$ & $1.09 \pm 0.17$ & 1.50 & 0.67 & 0.65 & 0.58 \\
\hline A3 & G.R. & Red. & 1500 & $8.30 \pm 0.13$ & $1.11 \pm 0.13$ & 3.64 & 0.97 & 0.60 & 0.56 \\
\hline A4 & G.R. & Ox. & 2100 & $8.35 \pm 0.06$ & $1.21 \pm 0.17$ & 1.12 & 3.68 & 0.88 & 0.66 \\
\hline A4 & G.R. & Red. & 1100 & $8.48 \pm 0.07$ & $1.16 \pm 0.15$ & 0.74 & 0.94 & 0.62 & 0.54 \\
\hline A5 & G.R. & Ox. & 1600 & $8.26 \pm 0.16$ & $1.20 \pm 0.11$ & 0.96 & 1.97 & 0.78 & 0.70 \\
\hline A5 & G.R. & Red. & 1450 & $8.33 \pm 0.16$ & $1.11 \pm 0.13$ & 0.74 & 2.20 & 0.67 & 0.51 \\
\hline A6 & G.R. & Ox. & 2100 & $8.19 \pm 0.19$ & $1.01 \pm 0.21$ & 0.95 & 1.08 & 0.73 & 0.65 \\
\hline A6 & G.R. & Red. & 1500 & $8.27 \pm 0.12$ & $1.18 \pm 0.14$ & 0.44 & 0.66 & 0.51 & 0.50 \\
\hline A7 & $\mathrm{H}$. & Red. & 3800 & $7.78 \pm 0.11$ & $1.16 \pm 0.02$ & 0.28 & 0.16 & 0.23 & 0.21 \\
\hline A8 & H. & Red. & 3000 & $7.90 \pm 0.07$ & $0.89 \pm 0.02$ & 0.19 & 0.22 & 0.23 & 0.17 \\
\hline A9 & $\mathrm{H}$. & Red. & 2700 & $7.84 \pm 0.13$ & $1.13 \pm 0.02$ & 0.24 & 0.20 & 0.24 & 0.18 \\
\hline A9 & H. & Red.2 & 2900 & $7.88 \pm 0.15$ & $1.14 \pm 0.02$ & 0.27 & 0.26 & 0.27 & 0.14 \\
\hline A 10 & $\mathrm{H}$. & Red. & 4000 & $7.71 \pm 0.14$ & $0.93 \pm 0.02$ & 0.38 & 0.28 & 0.28 & 0.17 \\
\hline A 10 & H. & Red.2 & 4200 & $7.64 \pm 0.15$ & $1.03 \pm 0.02$ & 0.29 & 0.25 & 0.27 & 0.20 \\
\hline L1 & B.M. & $\mathrm{Ox}$ & 2300 & $7.94 \pm 0.12$ & $0.91 \pm 0.02$ & 0.74 & 0.59 & 0.72 & 0.56 \\
\hline L2 & B.M. & Ox. & 3300 & $7.91 \pm 0.15$ & $1.08 \pm 0.02$ & 0.72 & 0.55 & 0.56 & 0.50 \\
\hline L3 & B.M. & Red. & 1950 & $8.13 \pm 0.08$ & $1.08 \pm 0.02$ & 0.70 & 0.52 & 0.56 & 0.33 \\
\hline L4 & B.M. & $O x$ & 2800 & $7.85 \pm 0.13$ & $1.09 \pm 0.02$ & 0.77 & 0.64 & 0.59 & 0.55 \\
\hline L5 & B.M. & Ox. & 2700 & $7.88 \pm 0.11$ & $1.05 \pm 0.02$ & 0.81 & 0.56 & 0.61 & 0.54 \\
\hline L6 & G.R. & - & 2400 & $8.36 \pm 0.11$ & $1.07 \pm 0.02$ & 0.62 & 0.53 & 0.53 & 0.56 \\
\hline L7 & G.R. & - & 2600 & $8.48 \pm 0.06$ & $0.93 \pm 0.02$ & 0.62 & 0.60 & 0.60 & 0.56 \\
\hline L8 & G.R. & - & 2000 & $7.93 \pm 0.25$ & $1.18 \pm 0.02$ & 0.86 & 0.55 & 0.49 & 0.39 \\
\hline
\end{tabular}

${ }^{*}$ G.R. = Grote Rug, H. = Haringvliet, B.M. = Brielse Meer.

equation (1) does not hold and that the $E_{t}$-value has been overestimated.

Inspection of the results from the last four columns in Table 6 gives little support to an alternative explanation of the effect of $\mathrm{CH}_{2} \mathrm{O}$ on $E_{t}$, that is that $\mathrm{CH}_{2} \mathrm{O}$ decreases the exchangeability of phosphate in a purely inorganic system. For instance, no suppression of exchangeability is noticed in cores A7-A10. We are therefore confident that $\mathrm{CH}_{2} \mathrm{O}$ inhibits bioactivity without complicating side-effects.

It is confirmed once more that in analysing for isotopically exchangeable phosphate one must add a biological inhibitor in order to prevent interference from bioactivity.

Columns 3 and 4 in Table 6 show that the results for the duplicate experiments in the presence of $0.17 \mathrm{M} \mathrm{CH}_{2} \mathrm{O}$ are not quite the same. The values for $E_{t}$ in column 4 are on average systematically 0.08 lower than those in column 3 . The reason is that the experiments were not carried out under the same state of agitation of the suspensions. Much better agreement between duplicates is obtained when the experimental conditions are identical (cf. foregoing paragraphs).

Comparison of the total exchangeabilities of phosphate in the presence of $\mathrm{CH}_{2} \mathrm{O}$ (Table 6) shows that the sediments collected from the Haringvliet have the lowest $E_{t}$ values (about 15-25\%) whereas high $E_{t}$ values (about 40-80\%) are found in the sediments from the Brielse Meer and the Grote Rug. Consequently the bioavailability of phosphate in the sediments collected from the Brielse Meer and the
Grote Rug can be assumed to be higher than in the sediments from the Haringvliet.

In the group of sediment cores $\mathrm{Al}$ - $\mathrm{A} 6$ and $E_{t}$-value of the reduced zone is, in the presence of $\mathrm{CH}_{2} \mathrm{O}$, systematically lower than the $E_{l}$-value of the oxidized zone in the same core. This indicates that phosphate in the reduced zone is fixed in a different manner. Apparently phosphate adsorbed on iron oxyhydroxide phases in the oxidized zone takes part in the isotopic exchange.

The high total isotopic exchangeabilities of phosphate found in most of the sediments of this study agree well with the results of Li et al. (1972, 1973) which were also obtained with freshwater sediments.

\section{CONCLUSION}

In order to get useful results on the isotopic exchangeability of phosphate present in different phases in sediments or soils, it is necessary to carry out the experiments under well defined conditions of $\mathrm{pH}$ and solid/solution-ratio. A biological inhibitor like formaldehyde must be added to prevent interference from bioactivity. Only then one can compare the results for different samples and correlate them with results obtained in various experiments on bioavailability of phosphate in these samples.

Acknowledgements - Parts of this investigation were commissioned by the Deltadienst of the Ministry of Transport and Public Works (Project 106). Drs J. P. Al and G. T. M. van Eck of the Deltadienst kindly placed sediments at our disposal, assisted in some chemical analyses. and did useful 
suggestions. The constructive comments on the first manuscript by two anonymous reviewers was very helpful in improving the presentation of the results.

\section{REFERENCES}

Amer F. (1962) Determination of ${ }^{32} \mathrm{P}$ exchangeable phosphorus in soils. Proceedings of the Symposium on the use of Radioisotopes in Soil-Plant Nutrition Studies, Bombay. 26 February-2 March. I.A.E.A. Proceedings Series, pp. 43-58.

Amer F., Mahdi S. and Alradi A. (1969) Limitations in isotopic measurements of labile phosphate in soils. $J$. Soil Sci. 20, 91-100.

Armstrong F. A. J. and Tibbits S. (1968) Photochemical combustion of organic matter in seawater for nitrogen, phosphorus and carbon determination. J. mar. biol. Ass. U.K. 48, 143-152.

Armstrong F. A. J., Williams P. M. and Strickland J. D. H. (1966) Photo-oxidation of organic matter in seawater by ultra-violet radiation, analytical and other applications. Nature 211, 481-483.

Atkinson R. J., Posner A. M. and Quirk J. P. (1972) Kinetics of isotopic exchange of phosphate and the -FeOOH-aqueous solution interface. J. inorg. nucl. Chem. 34, 2201-2211.

Becket P. H. T. and White R. E. (1964) Studies on the phosphate potentials of soils-III. The pool of labile inorganic phosphate. Pl. Soil 3, 253-282.

Bowman R. A. and Olsen S. R. (1979) A reevaluation of phosphorus-32 and resin methods in a calcareous soil. Soil Sci. Soc. Am. J. 43, 121-124.

Bowman R. A., Olsen S. R. and Watanabe F. S. (1978) Greenhouse evaluation of residual phosphate by four phosphorus methods in neutral and calcareous soils. Soil Sci. Soc. Am. J. 42, 451-454.

De Bussetti S. G., Ferreiro E. A. and Helmy A. K. (1977) Isotopic exchange of phosphate on some phosphatic compounds. J. Soil Sci. 28, 610-622.

Dalal R. C. and Hallsworth E. G. (1977) Measurement of isotopic exchangeable soil phosphorus and interrelationship among parameters of quantity, intensity and capacity factors. Soil Sci. Soc. Am. Proc. 41, 81-86.

Eisenreich S. J., Bannerman R. T. and Armstrong D. E. (1975) A simplified phosphorus analysis technique. Envir. Lett. 9, 43-53.

Harm W. (1980) Biological Effects of Ultraviolet Radiation. Cambridge University Press.

Hieltjes A. H. M. and Lijklema L. (1980) Fractionation of inorganic phosphates in calcareous sediments. $J$. entir. Qual. 9, 405-407.

Jackson T. A. and Schindler D. W. (1975) The biochemistry of phosphorus in an experimental lake environment: evidence for the formation of humic-metal-phosphate complexes. Verh. int. Verein. Limnol. 19, 211-221.

Kucey R. M. N. and Bole J. B. (1984) Availability of phosphorus from 17 rock phosphates in moderately and weakly acidic soils as determined by ${ }^{32} \mathrm{P}$ dilution, $\mathrm{A}$ value, and total P uptake methods. Soil Sci. 138, 180-188.

Le Mare P. H. (1981) Exchangeable phosphorus, estimates of it from amorphous iron oxides, and soil solution phosphorus, in relation to phosphorus taken up by maize. J. Soil Sci. 32, 285-299.

Li W. C., Armstrong D. E. and Harris R. F. (1973) Measurement of exchangeable inorganic phosphate in lake sediments. Entir. Sci. Technol. 7, 454-456.

Li W. C., Armstrong D. E., Williams J. D. H., Harris R. F. and Syers J. K. (1972) Rate and extent of inorganic phosphate exchange in lake sediments. Soil Sci. Soc. Am. Proc. 36, 279-285

Mekhael D., Amer F. and Kadry L. (1965) Comparison of isotopic dilution methods for estimation of plantavailable soil phosphorus. Proceedings of the Symposium on the use of the Isotopes and Radiation in Soil-Plant Nutrition Studies. Ankara, 28 June-2 July. I.A.E.A. Proceedings Series, pp. 437-448.

Murphy J. and Riley J. P. (1962) A modified single solution method for the determination of phosphate in natural waters. Analytica chim. Acta 27, 3136.

Murmann R. P. and Peech M. (1969) Effect of $\mathrm{pH}$ on labile and soluble phosphate in soils. Soil Sci. Soc. Am. Proc. 33, 205-210.

Pomeroy L. R., Smith E. E. and Grant C. M. (1965) The exchange of phosphate between estuarine water and sediments. Limnol. Oceanogr. 10, 167-172.

Ryden J. C. and Syers J. K. (1977) Origin of the labile phosphate pool in soils. Soil Sci. 123, 353-361.

Ryden J. C., Syers J. K. and McLaughlin J. R. (1977) Effect of ionic strength on chemisorption and potential determining sorption of phosphate by soils. J. Soil $\mathbf{S c i}$. 28, 62-71.

Sims J. R. and Haby V. A. (1971) Simplified colorimetric determination of soil organic matter. Soil Sci. 112, $137-141$.

Stumm W. and Morgan J. J. (1981) Aquatic Chemistry, 2nd edition. Wiley-Interscience, New York.

Syers J. K.. Harris R. F. and Armstrong D. E. (1973) Phosphate chemistry in lake sediments. J. envir. Qual. 2, $1-14$.

Venkat Reddy N., Saxena M. C. and Scrinivasulu R. (1982) E- L- and A-values for estimation of plant-available soil phosphorus. Pl. Soil 69, 311 .

White R. E. and Taylor A. W. (1977) Effect of $\mathrm{pH}$ on phosphate adsorption and isotopic exchange in acid soils at low and high additions of soluble phosphate. $J$. Soil. Sci. 28, 48-61. 